\title{
Mateludicando na educação infantil: um modelo de prática pedagógica para crianças pequenas
}

\author{
Matheplayful in kindergarten: the model of teaching practice \\ for small children.
}

\author{
Claudionor Renato da Silva \\ claudionorsil@gmail.com
}

\begin{abstract}
Resumo
Este artigo objetiva apresentar um modelo de prática pedagógica, ainda em desenvolvimento, denominado Mateludicando. Referenciado na Filosofia, a partir da obra de J. Huizinga, na conceituação do Modelo, se fazem aproximações entre as várias expressões do lúdico (as artes) com a Educação Matemática, com os saberes matemáticos na Educação Infantil. Particularizando o Modelo na Literatura Infantil com conteúdo matemático apresenta-se uma aplicação para crianças de 0-6 anos. O artigo assume, assim, que Mateludicando traz implicações ao currículo da educação infantil, por um lado, e à formação de professores em cursos de pedagogia, por outro, abrindo, assim, um campo de pesquisas para aplicação e avaliação do Modelo na Educação Infantil que pode também ser pensado para o Ensino Fundamental.
\end{abstract}

Palavras-chave: Mateludicando. Educação Matemática. Práticas Pedagógicas. Crianças Pequenas.

\begin{abstract}
In this article has the objective to present the Model of teaching practice, yet in development, called Matheplayful. Referenced in Philosophy from J. Huizinga's work in the conceptualization of Model are made between various expressions of playful (the arts) with Mathematics education. Particularizing the Model in Children's Literature with content mathematics presents an application for children aged 0 to 6 years. The article assumes, therefore, that Matheplayful has implications to the curriculum of Kindergarten on the one hand and for teachers formation in pedagogy courses the other hand, thereby opening up a search fields to implementation and evaluation Model in in Kindergarten it can also be thought of for Midle School.
\end{abstract}

Keywords: Matheplayful, Mathematics education. Teaching practices. Small Childrens.

\section{Palavras Iniciais}

Mateludicando, mateludicar são terminologias de um Modelo para práticas pedagógicas. Uma proposta lúdica de ensino-aprendizagem em matemática na educação infantil que pode ser estendida aos Anos Iniciais. Ludicidade expressa por meio dos jogos, da poesia, da literatura, das artes cênicas, da dança, da música e outras expressões artísticas, linguísticas e corporais, em uma fundamentação na Filosofia, em J. Huizinga.

A ludicidade no ensino de matemática é um tema recorrente, pois ocupa uma evocação singular do prazer em aprender matemática e o entendimento de sua aplicabilidade prática, no 
dia a dia. O recorte do Mateludicando neste artigo será na literatura infantil matemática ou literatura infantil com conteúdo matemático.

A REVEMAT publicou um único artigo sobre a literatura matemática na Educação Infantil com Palhares; Azevedo (2010). Estes autores da Universidade do Minho, com uma profundidade referencial sobre a literatura matemática na escola da infância, no âmbito europeu, elaboram uma abordagem que denominam de "abordagem terceira", para além da tradicional $^{1}$ e da construtivista ${ }^{2}$ no ensino de matemática na educação infantil, por meio da literatura. Segundo os autores, a ideia é partir de qualquer título da literatura infantil e a partir daí serem elaborados problemas matemáticos para serem dialogados e construídos junto com as crianças de 3 a 6 anos, organizando jogos.

A produção destes pesquisadores em Portugal aproxima-se ao que se pretende com este Ensaio, na continuidade de possibilidades de pesquisa com este enfoque: o da literatura infantil matemática. Esta tem sido a saída que muitos trabalhos, tanto em Portugal quanto aqui no Brasil como os de Neuenfeldt (2006), Juliani (2007), Oliveira; Passos (2008), Souza; Oliveira (2010), Menezes (2011), Rodrigues (2011) ${ }^{3}$, Fagundes (2012), Silva (2012), Filipe (2012).

O presente ensaio é um pouco na direção desta produção do ano de 2010 da REVEMAT no sentido de ser efetuada também uma proposta (um Modelo) para uso da literatura infantil matemática na educação infantil, mas abrangendo outras artes e produções ou áreas, como recursos para o ensino da matemática lúdica; uma ação de mateludicar... Mateludicando.

Subdividindo-se em três partes, o presente Ensaio em "Palavras Iniciais" - item 1, primeira parte - realiza uma discussão pautada na Educação Matemática e na Educação Infantil, a partir de Silva (2013) e Cerquetti-Aberkane; Berdonneau (1997), trazendo para a análise, autores da área da Educação Infantil. A segunda discussão das "Palavras Iniciais" é um trabalho bem mais refinado, no sentido de apresentar um referencial não muito lido nos cursos de Pedagogia, mas que se entende ser um referencial pertinente para conceituação de lúdico e ludicidade: Johan Huizinga. O Ítem 2, segunda parte do Ensaio, trata exclusivamente do Mateludicando; a proposta é a apresentação do Mateludicar na educação infantil, fugindo das

\footnotetext{
${ }^{1}$ Esta conceituação é expressa no artigo numa proposta abstrata de ensino de matemática - atualizando esta conceituação, os pesquisadores portugueses explicitam que este "abstrato" deve ser permeado pelo concreto.

2 Tendência construtivista para estes autores é assumida como o conhecimento construído pelo indivíduo autonomamente - referência em Piaget.

${ }^{3}$ Nesta dissertação, Maria Paula P. Rodrigues trabalha com históricas com conteúdos da espacialidade, ideias geométricas.
} 
convencionais práticas pedagógicas no eixo dos saberes da Matemática como contar com as crianças de 0 a 10 ou cantar a musiquinha da "Mariana conta 1, conta $2 . .$. ". Nada de errado nisto, mas a ideia do direito das crianças de acesso aos conhecimentos científicos matemáticos e sua identificação de necessidade para vida, na forma de saberes, são muito mais amplos do que isto e o Mateludicando é esta primeira aproximação prática - e para a prática, um Modelo - buscando uma ação docente em Educação Matemática para crianças pequenas em uma das muitas vertentes possíveis de expressão artístico-corporal, mas destacando para este ensaio: a literatura matemática infantil. A última parte do Ensaio (Ítem 3) são três considerações gerais sobre o Modelo Mateludicando, indicando as possibilidades de pesquisa e maior sistematização teórico-metodológica do Modelo.

Espero com este ensaio iniciar reflexões e receber contribuições críticas e construtivas para amadurecimento desta proposta para o currículo de formação de professores em cursos de Pedagogia e a prática pedagógica de educação das crianças pequenas na escola da infância no eixo Matemática.

\section{Educação Matemática Na Educação Infantil - Os Saberes.}

Silva (2013) aponta três frentes de saberes que os professores devem dominar, que envolvem o ensino-aprendizagem de Matemática para as crianças na escola da infância: a frente dos conteúdos e saberes da área da Matemática; a segunda frente tem a ver com conteúdos referentes à gestão da aula de matemática, portanto, referenciais na Didática Geral; a última frente é a dos conteúdos e saberes nos aportes da psicopedagogia ou, a forma como as crianças aprendem, com forte base na Psicologia da Educação, principalmente, Piaget - mas é preciso avançar em outras vertentes como a russa (Escola de Vygotsky) e a Teoria Bioecológica de Bronfenbrenner, para citar algumas outras possibilidades além da tradicional vertente piagetiana.

Isto impõe um perfil de docente que possua atitudes, competências e habilidades em Educação Matemática voltada para a criança pequena: nos conteúdos (o que e como ensinar); no processo de ensino-aprendizagem - Didática - (planejamento, execução e avaliação do Plano de Ensino e do Plano de Aula) e, principalmente, atitudes, competências e habilidades para lidar com os infantis. Isto equivale dizer, que este professor/a tem que ter muito claramente a concepção adotada para a sua prática quanto aos conceitos de infância, de criança e de educação infantil. 
Esta formação, na ideia de "saberes relativos ao edifício matemático" (Panizza apud Silva, 2013) prima por uma educação matemática na educação infantil, particularmente, do que deve ser a constituição e a proposta curricular da disciplina Fundamentos e Métodos da Matemática, nos cursos de Pedagogia.

Diferentemente da "cara" do Ensino Fundamental, na escola da infância, matemática não é "lugar-aula" ou um "tempo-aula". Matemática é oralidade, é brincadeira, é diálogo incansável, é a manipulação de diversos objetos “(...) que uma vez incorporadas favorecem a compreensão matemática escolar que prosseguirá nas etapas seguintes da escolarização (SILVA, 2013, p. 37)".

Cerquetti-Aberkane; Berdonneau (1997) apontam a administração mental como prática indispensável para a construção dos saberes das percepções - elementos do ensinoaprendizagem de Matemática na Educação Infantil. Elas utilizam o termo evocação e o classificam como “(...) a primeira e a mais importante das atitudes mentais que podemos trabalhar desde a Pré-Escola (...) que consiste em lembrar mentalmente no presente uma percepção anterior (p.14)”.

Atenção gera evocação que culmina na memorização e consequente compreensão.

\begin{abstract}
"A compreensão é uma atividade mental complexa: "para compreender, o sujeito começa por prestar atenção: olha e escuta com o projeto de evocar". Depois ele confronta a evocação que acaba de construir com o objeto da percepção. As comparações e os julgamentos que ele emite por ocasião desta confrontação servem de trampolim para a intuição do sentido (p.16)".
\end{abstract}

Estes elementos estão presentes na literatura infantil matemática, promovendo saberes e percepções. As autoras indicam a literatura infantil como recursos para organizar e incentivar evocações em processos de ensino-aprendizagem de matemática para crianças pequenas.

Oliveira (2011) afirma que uma proposta correta, ideal para a educação da criança na educação infantil, para o seu desenvolvimento, deve estar comprometida sempre, em primeiro lugar, com as interações criança-criança. Para esta autora o currículo, portanto, as práticas pedagógicas, devem estar articuladas ao dia a dia da criança e a ênfase repousar sobre processos, ou seja, “(...) nova concepção de currículo, entendido como trajetória de exploração partilhada de objetos de conhecimento de determinada cultura por meio de atividades diversificadas constantemente avaliadas (p.185)".

O ensino-aprendizagem da matemática ou a educação matemática para as crianças pequenas deve estar firmemente pautado nos "contextos de aprendizagem significativa" com atividades 
diversas e criativas, promovendo o desenvolvimento infantil integral que, em suma, não está desvinculado da matemática, já que o cognitivo, nesta fase, é de suma importância para constituição do "eu” infantil no mundo e, portanto, da organização lógica do pensamento (OLIVEIRA, 2011).

Neste sentido, do que Zilma de Oliveira assevera para o currículo da educação infantil, do qual os saberes da educação matemática se enquadram, visando a formação infantil, vale a pena as constatações de Rizzo (2003) e de Gonzalez-Mena; Eyer (2014 ) sobre as linguagens infantis e a construção lógico-matemática, desde os bebês. Para Rizzo (2003):

\begin{abstract}
"A inteligência lógico-matemática é fruto de uma longa construção de conceitos a respeito de relações de grandeza, mas a capacidade para esse tipo de realização nasce com o homem e precisa ser convenientemente estimulada e utilizada para não ficar embotada. A construção do número como representação de quantidades descontínuas (adequado à primeira infância) será a meta principal, o que envolverá outros conteúdos (...). Os jogos inteligentes, as situações lúdicas, observar, contar e comparar grandezas, classificar elementos e construir conjuntos deverão ser uma constante propiciada pelos eventos naturais do dia-a-dia da vida dentro da creche (p.90)".
\end{abstract}

Para Rizzo (2003) as aprendizagens matemáticas são também de expressão oral, logo, relações possíveis com a literatura. São também sentimentos e ideias. Indispensáveis. Envolvem: observação, classificação, comparação, ordenação, seriação, indagação, investigação, questionamentos, discussão de ideias e opiniões diante de problematizações propostas, memória (conforme Cerquetti-Aberkane; Berdonneau, 1997) por meio de músicas, prosas, poemas/poesias.

A recomendação de Rizzo sobre o tempo de atenção das crianças é importante nas atividades de literatura matemática (Quadro 1).

Quadro 1: Tempo de Atenção Dirigida da Criança

\begin{tabular}{|l|c|c|}
\hline IDADE (anos) & DURAÇÃO MÉDIA (min) & DURAÇÃO MÁXIMA (min) \\
\hline Até 1 & 1 a 2 & 3 \\
\hline De 1 a 2 & 2 a 3 & 4 \\
\hline De 2 a 3 & 2 a 4 & 5 a 8 \\
\hline De 3 a 4 & 3 a 8 & 10 a 15 \\
\hline De 4 a 5 & 4 a 10 & 15 a 20 \\
\hline
\end{tabular}

Fonte: reproduzido de Rizzo (2003, p.100)

Gonzalez-Mena; Eyer (2014) ao se referirem à linguagem infantil, seu desenvolvimento, fornecem uma boa base para a relação literatura e matemática, uma vez que, como afirmam:

"Além de facilitar a comunicação, a linguagem tem um impacto fortíssimo no pensamento e na cognição. Bebês e crianças conseguem "pensar" antes de adquirir 
linguagem, mas, quando as crianças realmente começam a usar a linguagem, as

habilidades cognitivas delas dão um grande passo adiante (p. 185)".

Assim, é que, para as autoras, a literatura é uma fonte de grande estímulo à leitura para crianças pequenas. "Jogue jogos que envolvam sons e palavras. Conte histórias, cante músicas e recite ou invente rimas e poemas (p. 189)".

Este primeiro subitem das Palavras Iniciais é a base das reflexões do Modelo Mateludicando, ou seja, a educação matemática para crianças pequenas (4-6 anos) e crianças bem pequenas (0-3 anos). A próxima base, importante é o lúdico, enquanto conceito na Filosofia.

\section{O Lúdico Em Johan Huizinga. Articulações (Im) Possíveis Em Literatura Matemática Para Crianças Pequenas}

Procurarei aqui referenciar lúdico em Johan Huizinga. Este autor não muito lido na Pedagogia traz importantes contribuições filosóficas para uma conceituação de lúdico e de ludicidade e sua aplicabilidade conceitual nas artes, na poesia e, para este ensaio, uma aplicabilidade conceitual para práticas pedagógicas em literatura infantil matemática nos espaços da escola da infância. Ao assumir este referencial, se discorda de algumas produções, como de Romera et al. (2007) que afirma que Huizinga não vê o lúdico expresso nos jogos como atividades enriquecedoras de ensino aprendizagem, tal como fazem alguns outros filósofos, mas muito mais, os psicólogos clássicos da educação. Ora, a obra de Huizinga não está discutindo educação, logo acusar a obra de uma relegação ao contexto educacional é o mesmo que acusar um inocente de um crime que não fez. Segunda justificativa: seria preciso no texto citado, aprofundar-se no pensamento de Huizinga que nos mostra muito bem que o papel da escola foi extinguir o lúdico, ocultá-lo e nos lembra muito bem que o início das Universidades no período Medieval se constituía de práticas lúdicas na aprendizagem da ciência daquele tempo. O que Huizinga não faz e tentamos fazer aqui é transpor o seu Homo ludens para as práticas educativas, recuperando assim, a defesa lúdica na aprendizagem, tal como fizeram os filósofos - e muito bem - Platão, Aristóteles, Montaigne e Rosseau e, mais recentemente (século XX) Fröebel. Demonstra-se no presente texto que são infundáveis as afirmativas de Romera et al. (2007) e, neste sentido, o Homo Ludens encaixa-se em práticas lúdicas, que por meio de jogos, promovem a formação e o desenvolvimento infantil escolar, sobretudo na aprendizagem de saberes da língua materna e dos símbolos matemáticos, bem como, sua lógica de pensamento, para se compreender, apreender e agir no e sobre o mundo. 
Mas o que é lúdico para Huizinga? Remontando-se ao contexto histórico e teórico epistemológico da Filosofia, fundamentalmente a lógica, lúdico é sinônimo e essência do jogo: jogo da retórica, jogo da lógica, jogo da oralidade, jogo da competição. Jogos caracteristicamente infantis no geral, mas particularizado/diferenciado, para Huizinga: para crianças pequenas, sinônimo de lazer ou brincadeira, para os adultos, algo sério e de alguma maneira "superior". Esta última, sendo uma das mais elevadas e gratificantes ações humanas, entre nobres, realizada por adultos; um modelo de oralidade pergunta-resposta, digamos, uma filosofia pura (HUIZINGA, 2000).

Podemos inferir então que o lúdico filosófico tem grande implicação na aprendizagem da lógica matemática por meio da oralidade, da dialogicidade, mas também, desenvolvimento infantil integral, considerando o jogo sem um "labor" filosófico, e sim, como um fator do desenvolvimento, um "ócio" tal como o sentido original da palavra "escola". É neste momento que penso que J. Huizinga nos ajuda a pensar uma literatura matemática que transmite e ensina saberes "infantilmente", entre adulto (professor/a) e criança (aluno/a). Exatamente quando nos apresenta dois tipos ou modelos de diálogo filosófico: o diálogo literário e o diálogo conversatório que, em síntese, se complementam por possuírem ou exprimirem, ambos, o lúdico.

\footnotetext{
"O que é a escrita?, pergunta Pepino, filho de Carlos Magno, e Aluíno reponde: "É a guardiã da ciência." "O que é a palavra?" - "A traição do pensamento." "Onde se originou a palavra?" - "Na língua." "O que é a língua?" - "Um chicote no ar." "O que é o ar?" - "É o guardião da vida." "O que é a vida?" - "A alegria dos felizes, a dor dos infelizes, a espera pela morte". "O que é o homem?" - "O escravo da morte, o hóspede de um só lugar, um viajante que passa." (HUIZINGA, 2000, s/p).
}

Não é exatamente este ludiciar que permeia o ambiente dos momentos de leitura e oralidade na educação infantil? As dúvidas que surgem das próprias dúvidas sobre a história lida ou contada pelo professor/a?

Outro apontamento histórico interessante de J. Huizinga é que a Universidade, em sua formação inicial, junto aos grandes conventos “(...) era eminentemente agonístico e lúdico (s/p)", ou seja, toda prática universitária medievalesca estava pautada na competição e na ludicidade.

Huizinga caracteriza a Arte, a poesia, a música e a dança como elementos lúdicos ou expressões de ludicidade. Ficaremos, para o caminho que traçamos para este ensaio, somente na poesia e daí para a literatura, como forma lúdica filosófica. Para o autor “(...) Mas, 
enquanto na poesia as próprias palavras elevam o poema, pelo menos em parte, do jogo puro e simples para a esfera da ideia e do juízo (...) (s/p)".

Aqui temos o encontro dos diálogos literário e conversatório, permeados, então e, absolutamente, pelas palavras, o texto. Que conduz, inevitavelmente, como propõe o autor, no momento do jogo que envolve pensamento, aprendizagem, raciocínio.

Pensemos então a leitura de uma obra literária infantil em matemática como um jogo, como um ludus (para os gregos), ludi (para os romanos) em que brincadeira e jogo são uma mesma ação, resultado. Definição de jogo para Huizinga: atividade livre, inicialmente "não-séria", mas que assume intencionalidade; momento de prazer e intensa afetividade.

Entre o que é válido para ensino e aprendizagem ou simplesmente a brincadeira, como algo não sério, como diz J. Huizinga, há algo que nos chama a atenção quanto ao texto escrito, a literatura - e neste sentido, um valor mais sério como jogo voltado à aprendizagem: o texto só tem valor se for possível ser representado e apresentado, ou seja, a arte literária ou discurso literário se transformar em arte cênica e arte oral, linguagem e, fundamentalmente: uma arte literária apresentada a um público. Uma ação!

Sobre a linguagem, a escrita e a falada, afirma Huizinga que no jogo assume fonte de elaborações matemáticas: designar, comparar, refletir.

A colocação da linguagem e do imaginativo "ao lado da natureza", segundo Huizinga, implica este lugar abstrato ora dado pela literatura ora inventado pelas crianças, em contato com a leitura, ocorrendo aí, simultaneamente ao entendimento da história, processos matemáticos de diferenciação, tempo-espaço, designação e, sobretudo, a metáfora e os jogos (as brincadeiras com as palavras).

Talvez a principal questão de Huizinga e que nos "cutuca" na educação seja: que saídas para o retorno do lúdico, principalmente na educação, nos processos de ensino-aprendizagem, na educação matemática com a literatura infantil? Primeiro: demarcação de limites, regras. Esta literatura precisa apresentar o jogo, suas regras e, portanto, elementos de cidadania em que os saberes matemáticos já se tornem necessários à vida em sociedade. Segundo: evocação da razão filosófica, permeada pela cultura escolar infantil e pela cultura multi dos educandos infantis. Terceiro: elimine a ordem política imposta ou os valores impositivos, permitindo a criação, o imaginativo e a abstração própria do universo infantil, neste caso, uma literatura libertária, mas fincada nos saberes matemáticos imprescindíveis à escolarização das crianças pequenas, percebendo a importância da matemática no dia a dia. 
A literatura matemática infantil, promovendo saberes, na ludicidade, encaminha brincadeiras, divertimento, possibilidade de construções de final de história diversas, etc., dado que, em qualquer cultura, o jogo, o lúdico, ultrapassa a racionalidade e, neste sentido, segundo Huizinga:

Mateludicando Na Educação Infantil - O Modelo. Uma Proposta Com Literatura Infantil Matemática Ou Literatura Infantil Com Conteúdo Matemático

\section{MATELUDICANDO - DEFINIÇÃO}

"Uma ação de ensino-aprendizagem em Educação Matemática, fundamentada na Filosofia. Uma ação compartilhada e vivenciada entre educadores(as) e educandos(as) infantis, na forma de saberes que focam a emergência do lúdico nas atividades pedagógicas intencionadas e planejadas na educação infantil, de acesso e permanência em momentos de manipulação e abstração de objetos ou símbolos na corporalidade, propiciando tanto as primeiras linguagens matemáticas como também as primeiras percepções matemáticas na demonstração de utilidade no dia a dia, de modo que o prazer e a afetividade sejam motores de potencializações de olhares à matemática como um conhecimento acessível, fácil, prazeroso e essencial à vida, por meio do jogo, da brincadeira, das artes cênicas, da música, da dança, da poesia, da literatura, expressões estas e outras possíveis, que, com objetos e corporalidades evocam a matemática, sua presença no mundo físico, sua essência científico-prática (Elaborado pelo Autor)”.

Alguns elementos a partir da definição dada. Elementos para a formação inicial em cursos de Pedagogia. Elementos em construção teórico-metodológica pelo autor:

A. Mudança de pensamento e atitude do professor(a) com relação à Matemática, sobretudo atitudes pessoais positivas com relação à Matemática; outra mudança de pensamento e atitude é com relação à Matemática na escola da infância.

B. Estudos (1) sobre os fundamentos da Educação Matemática e a especificidade voltada à Educação Infantil. Estender estes estudos, do $1^{\circ}$ ao $3^{\circ}$ Anos do Ensino Fundamental, na perspectiva do PNAIC $^{4}$; (2) sobre o lúdico na Filosofia.

C. Concepção de infância e criança na educação infantil e a perspectiva tríade do educar, cuidar e brincar. Inaugurar no campo da pedagogia concepções de pré-adolescência e adolescência, focando assim, o Mateludicando nas crianças de $1^{\circ}$ ao $3^{\circ}$ Anos do Ensino Fundamental, como também, $4^{\circ}$ e $5^{\circ}$ Anos, promovendo articulações ao PNAIC - esta última, uma possibilidade aberta, mas ainda não em curso, pois o foco, inicialmente, tem sido a Educação Infantil. 
D. Organização de atividades, práticas, performances, histórias, materiais paradidáticos, inicialmente, com aplicações reais, seguidas de registros, publicações, comunicações científicas, monografias, artigos, etc., de maneira que o Modelo de Prática Pedagógico do Mateludicando se sistematize teórica e metodologicamente.

E. Garantia de que o Direito aos saberes matemáticos científicos, na educação infantil - e nos Anos Iniciais - seja garantido às crianças e adolescentes.

\section{O MODELO}

O Modelo Mateludicando ainda está em fase de consolidação pelo autor, por meio de Projetos de Extensão de Contação de Histórias Infantis Matemáticas e gravação de aulas, bem como orientação de Iniciação Científica e Trabalhos de Conclusão de Curso, na graduação e pósgraduação latu sensu, Especialização. Neste momento inicial, apenas aplicações na Educação Infantil, como já esclarecido.

O Quadro 2 é a apresentação geral do Modelo em suas diferentes vertentes aplicativas voltadas para a Educação Infantil - que podem também serem aplicados nos Anos Iniciais. O Modelo está também sendo pensado, discutido na Formação Inicial em Cursos de Pedagogia, com aplicações em Escolas de Educação Infantil, seguida de Avaliações para futuro desenvolvimento de Material Didático e de Recursos.

Quadro 2: O Modelo Mateludicando - Prática Pedagógica na Educação Infantil

\begin{tabular}{|c|c|c|c|c|c|c|c|}
\hline \multicolumn{8}{|c|}{ MATELUDICANDO NA EDUCAÇÃO INFANTIL } \\
\hline MÚSICA & DANÇA & $\begin{array}{l}\text { POESIA, } \\
\text { CONTOS }\end{array}$ & TEATRO & $\begin{array}{c}\text { TABULEIROS, } \\
\text { ENCAIXES }\end{array}$ & $\begin{array}{c}\text { PERGUNTA/ } \\
\text { RESPOSTA }\end{array}$ & MÍMICA & LITERATURA \\
\hline \multicolumn{8}{|c|}{ CONTEÚDOS MATEMÁTICOS: } \\
\hline \multicolumn{8}{|c|}{ Números. Operações. Figuras e Formas. Tratamento da Informação. Grandezas e Medidas. } \\
\hline \multicolumn{8}{|c|}{ ELEMENTOS PRESENTES - Segundo J. Huizinga } \\
\hline \multicolumn{8}{|c|}{$\begin{array}{l}\text { - } \\
\text { - } \quad \text { Presençação do jogo, o jogo matemático. } \\
\text { (língua materna) e a linguagem científica matemática infantil - Metodologia do "pergunta-responde". } \\
\text { - } \quad \text { Exploração da lógica matemática, articulada assim, ao elemento anterior. No caso da literatura, } \\
\text { da poesia e da prosa: o diálogo literário transposto para o diálogo conversatório. } \\
\text { - } \quad \text { Presença constante da dúvida da dúvida e do infinito das possibilidades que emergem do texto ou } \\
\text { da apresentação cênica, verbal, dança ou música. }\end{array}$} \\
\hline
\end{tabular}

Fonte: Elaborado pelo Autor. 


\section{APLICAÇÃO - Literatura Matemática para Crianças Pequenas}

\section{Conceito de Literatura Infantil: articulações breves à Matemática}

Como já apontamos, muitos estudos vêm sendo realizados na área da Educação Matemática explorando a literatura, utilizando-a como recurso pedagógico e incentivo às primeiras experienciações em raciocínio matemático e resolução de problemas.

Algumas características da literatura infantil, segundo Filipe (2012):

“1) Destinar-se à infância, o que significa que, para que exista uma literatura infantil, é necessário que se configure uma ideia de infância;

2) $\mathrm{O}$ acervo de textos infantis recorre a um material pré-existente, mas que até então não se dirigia especificamente à criança, como os clássicos e os contos de fadas;

3) Incorporação de aspetos constitutivos dos contos de fadas, tais como a presença do maravilhoso e a peculiaridade de apresentar um 'universo em miniatura';

4) Atualmente as transformações ocorridas nos contos de fadas confundem-se com a literatura infantil, não se conseguindo mais pensar essas narrativas fora do âmbito exclusivo da literatura infantil;

5) A literatura infantil evidencia sempre as preocupações dos adultos para com a infância, revelando uma assimetria entre o autor adulto e o leitor infantil (p.46)".

A literatura infantil matemática, elaborada/formatada/criada ou aquela que se originará dos clássicos ou das produções já disponíveis no mercado, nas Bibliotecas ou na Internet terão que se caracterizar acima de tudo por (a) uma narrativa curta; (b) evocar sempre uma ação; (c) personagens e tempo dos "cenários" bem demarcados.

Filipe (2012) apresenta os sub-gêneros da Literatura Infantil, numa perspectiva portuguesa, que exemplifica como esta literatura vem sendo estudada e aplicada no ensino de matemática e ciências da natureza na escola para crianças pequenas. Trata-se dos sub-gêneros: rimas e canções; parábolas e fábulas; contos; mitos e lendas.

Os estudos no Brasil têm em comum a opinião de que atividades matemáticas explorando a literatura tem um efeito duplo: (1) aprendizagens matemáticas; (2) gosto pela leitura e formação de leitores (JULIANI, 2007; SOUZA; OLIVEIRA, 2010; SILVA, 2012).

Particularmente, na Educação Infantil:

“(...) o ensino de Matemática associado à Literatura Infantil, possibilita ao professor criar, em sua prática, situações na sala de aula que encorajem os alunos a compreenderem o que estão estudando, familiarizando-os com a linguagem matemática contida nos textos de literatura infantil, possibilitando ao aluno a capacidade de estabelecer relações cognitivas entre a linguagem materna, conceitos da vida real e a linguagem matemática formal (SILVA, 2012, p. 39)”. 
Há um acordo entre os autores aqui referenciados de que a linguagem matemática é anterior ao ingresso da criança na escola de educação infantil. Esta é uma perspectiva do letramento (aprendizagem da oralidade da língua materna - letras e alfabeto) e do numeramento (a aprendizagem dos números e operações, percepções matemáticas mentais e contato com o concreto) (SOUZA; OLIVEIRA, 2010).

Machado (2001), Bicudo; Guarnica (2001), dentro muitos outros autores são importantes referenciais sobre a interrelação e a indispensável articulação entre Matemática, Língua Materna e Literatura, perpassando a Filosofia da Matemática.

Sobre a produção de Histórias Infantis com conteúdo matemático, o estudo de Oliveira; Passos (2008) faz referência a duas obras de Katia Smole, fundamentais para a área da educação infantil: Smole; Cândido; Stancanelli (1999), Smole (2000), Smole e Diniz (2001) e Smole (2004). Nestes trabalhos aprofundam-se teórica e metodologicamente as relações entre literatura infantil e aprendizagens matemáticas.

Oliveira; Passos (2008) cita, por exemplo, Aritmética da Emília de Monteiro Lobato em que o autor faz referência à obra de $O$ homem que calculava de Malba Tahan: “(...) através de suas obras mostram-nos que a matemática pode ser ensinada por meio de nossa capacidade imaginativa e criativa de contar históricas (OLIVEIRA; PASSOS, 2008, p. 320)”.

Em Aritmética da Emília, segundo as autoras, encontra-se um bom ponto de partida para práticas pedagógicas em literatura infantil matemática. O estudo de Oliveira; Passos (2008) é um incentivo à produção de livros paradidáticos de literatura infantil matemática.

Nos países anglófonos e também em Portugal, segundo Menezes (2011), o uso da literatura matemática infantil e juvenil já vem de longas datas. No Brasil, só recentemente vem sendo publicadas obras “(...) em prosa e em verso, de diversos livros que reúnem condições para serem explorados em salas de aula de Matemática (p.69)". A autora cita: Figuras Figuronas de Maria Alberta Menéres; O Pequeno Livro de Desmatemática de Manuel Pina; Histórias com Matemática I de L. Menezes et al.

Assim, finaliza-se esta rápida consideração teórica sobre a literatura infantil matemática afirmando sobre os ganhos da Matemática e da Língua Materna nas aprendizagens de saberes da literatura na educação infantil.

\section{O Modelo Mateludicando (Prática Pedagógica) da Literatura Infantil para crianças bem pequenas ( $(0$ a 3$)$ e crianças pequenas ( 4 a 6 anos).}

Qual proposta pedagógica se apresenta então, a partir do Modelo (Quadro 2), num recorte na Literatura Matemática Infantil? A proposta se fundamenta nestes pontos básicos e simples: 
- Escolha da literatura. Alguns requisitos para a escolha: (1) Para bebês e crianças bem pequenas (0-3 anos). (2) Para crianças pequenas (4-6 anos).

- A obra literária escolhida deverá atender ao Quadro 2.

- Leitura-treino na forma de contação com rítmica, alteração de voz, uso optativo de fantoche ou personagens reais - aí aproximamos propostas nas artes cênicas.

- Convite ao público infantil ou ida ao espaço escolar infantil para a leitura e interação com as crianças pequenas.

- Momento Avaliativo da leitura. Diversas possibilidades, mas a principal é a exploração da oralidade, por exemplo, as crianças criando novas formas de final de história. No caso de bebês, registrar as expressões, as ações. Estas podem ser primeiramente gravadas e depois analisadas ou deixando os livros com elas proceder à Observação e registro das ações dos bebês, sozinhos e entre eles em contato com o livro.

Alguns livros para aplicações do Modelo Mateludicando (Literatura Infantil Matemática), além dos apresentados ao longo do texto, têm-se seguir: O título da obra e Editora. Estes títulos foram extraídos de Juliani (2007) e Menezes (2011). Obras: Chico Bento e a pescaria, Melhoramentos; Farra no formigueiro, Ática; A fábula das três cores, Melhoramentos; Clact... Clact..., Ática; O Ratinho e os números, Melhoramentos; O pirulito do pato, Scipione.

O planejamento de aplicação do Modelo, então, segue a leitura inicial destas obras e sua adequação aos elementos do Quadro 2 em que julgo imprescindível, que o professor seja um bom contador de histórias! A leitura da literatura terá que ser muito envolvente.

\section{Considerações Gerais Finais}

- Considerações sobre o Modelo Mateludicando. Em fase de construção teóricometodológica, como já afirmado, o Modelo organiza uma prática, sobretudo na educação infantil, em que, pretende-se superar a visão de senso comum de que não se deve "ensinar" matemática ou "a criança deve brincar na educação infantil". Concordo, mas não podemos supor que nas brincadeiras e vivências infantis propostas pelos professores(as) não haja aí princípios da ciência matemática. Ocultar isto das crianças é retirar-lhe o direito de perceber e evidenciar, desde cedo, que a matemática é parte essencial de sua formação e expressão nítida do mundo físico a que pertence e que com ele interage. Trata-se então de um modelo a ser ainda construído e aplicado e que contribui na educação infantil para uma prática mais ampla e séria no eixo Matemática. 
- $\quad$ O Mateludicando à formação docente para Educação Infantil e Anos Iniciais (universitária e continuada). Inicialmente a preocupação do modelo é com a formação inicial, mas pode ser aplicado à formação permanente, na modalidade de cursos de formação. E a justificativa é a mesma do item anterior e que se amplia num ponto inflexivo muito sério nos cursos de Pedagogia: a aversão dos licenciandos(as) com a Matemática, geralmente, quase sempre, com uma atitude negativa, uma atitude de inutilidade em que a defesa ou alívio se resume na ideia de que na prática, tudo se resolverá, pois o Livro Didático será a "salvação": só seguir! Estará tudo em "vermelho"... Tanto os processos de desenvolvimento das contas como o resultado! Assim, o Modelo Mateludicando permite ao docente em atuação e ao futuro docente em formação universitária encontrarem-se (pessoalmente) com a Matemática $\mathrm{e}$, neste processo, ao apresentarem às crianças pequenas a utilidade e a prazerosidade desta ciência na vida cotidiana, com toda certeza, estarão propiciando à estas estas crianças, um percurso escolar em Matemática, evidenciando sempre, sua praticidade a partir do raciocínio e da lógica pertinentes à vida em sociedade que logo, perceberão, que os cálculos matemáticos entendidos e aplicados são maneiras de explicação do mundo físico e de interpretação deste mundo e que, esta leitura de aplicabilidade é antes de tudo e, de fato, prioritariamente uma ato de pensamento, um ato lógico-matemático.

- A testagem/aplicação do modelo - pesquisas. Ainda segue em estudo e análise, sobretudo, no interesse de investigar que práticas os professores(as) vêm ensaiando e que mudanças o Modelo Mateludicando poderá inserir nestas práticas em exercício nos espaços da educação infantil. No caso dos Anos Iniciais que espaço o currículo permite ou permitirá esta proposta? Que articulações ou aproximações podem ser estabelecidas entre o Modelo e o PNAIC? Um campo de pesquisa parece estar aberto, então, para que os processos de ensinoaprendizagem em Matemática sejam prazerosos e coadunem-se com o dia a dia dos professores(as) e dos educandos(as), na percepção e aceitação de que a Matemática está em todo lugar e ao nosso redor e desde a Educação Infantil.

\section{Referências}

BICUDO, Maria Aparecida Viggiani. GUARNICA, Antônio Vicente Marafioti. Filosofia da Educação Matemática. Belo Horizonte: Autêntica, 2001.

CERQUETTI-ABERKANE, Françoise. BERDONNEAU, Catherine. O ensino da matemática na educação infantil. Porto Alegre: Artes Médicas, 1997.

FAGUNDES, Andréa Vassallo. Formação continuada na perspectiva da racionalidade comunicativa: possibilidades de articulação entre literatura infantil e o ensino de ciências da 
natureza. 351f. 2012. Programa de Pós-Graduação Educação para a Ciência. Faculdade de Ciências. Universidade Estadual Paulista Júlio de Mesquita Filho.

FILIPE, Rita Isabel Batista da Silva. A promoção do ensino de ciências através da literatura infantil. 203f. 2012. Mestrado. Área de Especialização em Didática das Ciências. Instituto de Educação. Universidade de Lisboa, 2012.

GONZALEZ-MENA, Janet. EYER, Dianne Widmeyer. O cuidado com bebês e crianças pequenas na creche. Um currículo de educação e cuidados baseado em relações qualificadas. 9a ed. Porto Alegre: AMGH, 2014.

HUIZINGA, Johan. Homo ludens. São Paulo: Perspectivas, 2000. Disponível em: < http://ir.nmu.org.ua/bitstream/handle/123456789/132550/68693b58d310bd9a99b0d9eed1594 84a.pdf?sequence=1 $>$. Acesso em 12 fev. 2015.

JULIANI, Mônica. Matemática e literatura. Resolução de situações-problema a partir de contos para crianças. Revista do Professor, Porto Alegre, 23 (90): 5-8, abr./jun., 2007.

MACHADO, Nilson José. Matemática e língua materna: a análise de uma impregnação mútua. $5^{\circ}$ ed. São Paulo: Cortez, 2001.

MENEZES, Luís. Matemática, literatura e aulas. Educação Matemática, p. 67-71, nov./dez., 2011.

NEUENFELDT, Adriano Edo. Matemática e literatura infantil: sobre os limites e possibilidades de um desenho curricular interdisciplinar. 195f. 2006. Mestrado. Programa de Pós-Graduação em Educação. Centro de Educação. Universidade Federal de Santa Maria, 2006.

OLIVEIRA, Rosa Maria Moraes Anunciato de. PASSOS, Cármem Lúcia Brancaglion. Promovendo o desenvolvimento profissional na formação de professores: a produção de histórias infantis com conteúdo matemático. In: Ciência e Educação, v. 14, nº 2, p. 315-330, 2008 .

OLIVEIRA, Zilma de Moraes Ramos de. Educação Infantil: fundamentos e métodos. $7^{\mathrm{a}}$ ed. São Paulo: Cortez, 2011.

PALHARES, Pedro. AZEVEDO, Fernando. Uma proposta de integração entre a matemática e a literatura infantil em contexto de jardim de infância. REVEMAT, Revista Eletrônica de Educação Matemática. Florianópolis, v. 05, n.1, p. 15-24, 2010.

RIZZO, Gilda. Creche: organização, currículo, montagem e funcionamento. $3^{\mathrm{a}}$ ed. Rio de Janeiro: Bertrand Brasil, 2003.

RODRIGUES, Maria Paula Pereira. Histórias com matemática: sentido espacial e ideias geométricas. 181f. 2011. Mestrado. Escola Superior de Educação de Lisboa. Instituto Politécnico de Lisboa, 2011.

ROMERA, Liana et al. O lúdico no processo pedagógico da educação infantil: importante, porém ausente. Movimento, Porto Alegre, v. 13, n. 02, p. 131-152, maio/agosto, 2007. 
SILVA, Adelmo Carvalho da. Literatura Infantil e a formação de conceitos matemáticos em crianças pequenas. Ciências \& Cognição, v. 17 (1), 37-57, 2012.

SILVA, Claudionor Renato da. Educação Matemática, Didática e Formação de Professores. Um diálogo com licenciandos em pedagogia e matemática. Jundiaí, SP: Paco, 2013.

SMOLE, Kátia Cristina Stocco. CÂNDIDO, Patrícia C. STANCANELLI, Renata. Matemática e literatura infantil. (Coleção Apoio). Belo Horizonte: Lê, 1999.

SMOLE, Kátia Cristina Stocco. et al. Era uma vez na matemática: uma conexão com a literatura infantil. São Paulo: CAEM/IME/USP, 2004.

SMOLE, Kátia Cristina Stocco. et al. A matemática na educação infantil: a teoria das inteligência múltiplas na prática escolar. Porto Alegre: Artes Médicas, 2000.

SMOLE, Kátia Cristina Stocco. DINIZ, Maria Ignez (orgs.). Ler, escrever e resolver problemas: habilidades básicas para aprender matemática. Porto Alegre: Artmed, 2001.

SOUZA, Ana Paula Gestoso de. OLIVEIRA, Rosa Maria Moraes Anunciato de. Articulação entre literatura infantil e matemática: intervenções docentes. Bolema, Rio Claro (SP), v. 23, no 37, p. 995-75, dez., 2010. 